\title{
Impact of monkey-human relationships and habitat change on Semnopithecus vetulus nestor in human modified habitats
}

\author{
Jinie D. S. Dela \\ No. 45, Gunatilleke Mawatha, Etambagoda, Panadura.
}

\begin{abstract}
Semnopithecus (Trachypithecus) vetulus nestor, (Family: Cercopithecidae, Sub-family Colobinae) the western purple-faced langur of Sri Lanka, is currently recognized as one of the world's 25 most endangered primate taxa as much of the free-ranging populations of this subspecies are found in human modified areas. Accordingly, this paper seeks to identify and assess the impact of monkey-human relationships on $S$. vetulus nestor, in areas where monkeys and humans co-occur, and to ascertain threats to these langur populations living outside natural forests.
\end{abstract}

Monkey-human conflicts were investigated in 1985 during a census of langurs at seven sites in and around Panadura and Piliyandala. More detailed data were gathered through direct observation of two habituated free ranging groups of $S$. vetulus nestor in home gardens and rubber monocultures at two study sites in Panadura and Piliyandala during a systematic study from 1985-1987. This was followed by opportunistic observations during 1987 - 1992 at the Panadura site. A questionnaire was administered to householders at these two sites in 1987, and habitat change was monitored periodically thereafter until 2006 at both sites.

The study revealed that loss of canopy cover due to habitat destruction was the most significant threat to $S$. vetulus nestor in human modified environments, followed by hunting, which varied in intensity at different sites. Live capture of monkeys as pets was not a threat at any of the investigated sites. Langurs caused damage to crops and tiled roofs, and were considered pests by $47.5 \%$ and $82.4 \%$ of householders at the two main study sites. Despite this, there was high tolerance towards langurs by householders at both study sites during the 1987 survey; less than $10 \%$ of the householders wanted monkeys destroyed; and fewer were willing to do so themselves. Most people at each site (63.1\% and 55.6\% at Panadura and Piliyandala respectively) harassed or chased monkeys only if they caused crop or roof damage. At both sites, food competition-mainly for human edible fruit-was the main cause of conflict, followed by roof damage.
The study sites exemplify scenarios in non-forested areas in the densely populated geographic range of $S$. vetulus nestor. This study, therefore, underscores the precarious existence of this Critically Endangered langur in human-modified habitats, which are vulnerable to change. Ensuring the survival of S. vetulus nestor requires addressing the major challenges of establishing linkages between isolated forest fragments in its range and maintaining adequate canopy cover and food trees in the main forest and modified habitats without further delay.

Keywords: Habitat fragmentation, human modified habitats, monkey-human conflicts, Semnopithecus vetulus nestor.

\section{INTRODUCTION}

The future survival of over half of the world's extant non-human primates are currently threatened; the major causal agents are human induced, namely: habitat destruction due to extensive deforestation; hunting for meat, body parts, or as agricultural pests; and live capture for export, local trade of young, or biomedical research (Eudey, 1987; Mittermeier \& Cheney, 1987; Oates \& Davies, 1994). The taxa most threatened are those with small population size and limited distribution, and/or are vulnerable to the impacts of expanding human populations and large scale development initiatives (Eudey, 1987). Langurs (leaf monkeys) belonging to the subfamily Colobinae (Family: Cercopithecidae) are among the most endangered primates, due to their high dependence on undisturbed forests for survival and the vulnerability of most species to habitat change (Oates \& Davies, 1994). Semnopithecus vetulus, a colobine endemic to Sri Lanka, is listed as globally threatened by IUCN (2011). This langur, one of three monkey species found in Sri Lanka (Brandon-Jones et al., 2004) is arboreal and confined to areas with high continuous canopy cover (Rudran, 1970; Dela, 1998). Of the four sub-species of 
S. vetulus currently recognized (Groves, 2001), S. vetulus philbricki inhabits dry zone forests, while the other three subspecies are allopatric in the Wet Zone (Hill, 1934; Phillips, 1981; Groves, 2001). The three wet zone subspecies occur in a region where deforestation has been severe (Gunatilleke \& Gunatilleke, 1985), and where only ca. $9 \%$ of the land area remains under natural forest (NARESA, 1991).

The range of $S$. vetulus nestor, termed the western purple-faced langur, covers the Colombo and Gampaha Districts, and limited areas of the Kalutara, Kegalle, Ratnapura and Kurunegala Districts in the wet western lowlands of the island (J.D.S. Dela, unpublished data). It is the most threatened of the four sub-species as its range falls within an area with very high human population density in the island (Department of Census and Statistics, 2001). The region in which S. vetulus nestor ranges is also devoid of sizeable primary forests due to tree felling for timber or total clearing (Gunatilleke \& Gunatilleke, 1985). A recent survey (2008-2010) of the geographic range of $S$. vetulus nestor revealed that the remaining forests are small, fragmented and isolated amidst areas of high human population density (J.D.S. Dela, Padmalal and Sathurusinghe, unpublished data). Only the Horagolla National Park (13.4 ha), is set aside strictly for protection (i.e. forests categorized as conservation forests, national parks, nature reserves or strict nature reserves), but this contains only a few individuals (J.D.S. Dela, unpublished data). While $S$. vetulus nestor populations range through several very fragmented patches of lowland rainforests, they are not confined to the forest boundaries, and much of its geographic range comprises human modified habitats such as home gardens and rubber monocultures (ibid). Furthermore, there has been a major change in socioeconomic levels and land use within the geographic range of $S$. vetulus nestor during the last century which led to a considerable change of land use patterns (MOFE, 1999; Dela, 2004). All these factors have contributed to a perceptible change in the human modified areas occupied by $S$. vetulus nestor, and it is therefore listed as Critically Endangered in the 2011 IUCN Global Red List (2011), and also recognized as one of the 25 most endangered primate taxa in the world (Mittermeier et al., 2005).

While it has been evoked that the main threat to nonhuman primates is habitat loss because of high human population pressure and the consequent demand for land (Dittus, 1977), there were no quantified data prior to this study on monkey-human relationships in Sri Lanka. This paper presents basic data on the relationship between $S$. vetulus nestor and humans that co-occur in two categories of land use that is common in the lowland
Wet Zone, namely home gardens and rubber plantations. It is recognised that the variety of habitat types within this region, combined with different socio-economic, cultural and religious factors, result in a diverse array of environmental conditions for primates. Hence, detailed data on monkey-human conflicts and habitat change at the two main study sites, supported by information gathered at six other sites surveyed less extensively, are presented as scenarios where $S$. vetulus nestor co-occurs with humans outside natural forests. The factors that govern monkey-human relationships in the scenarios presented in this paper are discussed in the context that they are applicable to situations elsewhere within the geographic range of $S$. vetulus nestor where similar environmental and socio-economic conditions prevail. This paper also highlights the main threats to this Critically Endangered sub-species and demonstrates the adverse impacts of habitat change and hunting on the future survival of this langur.

\section{METHODS}

Subjects and sites: The study of monkey-human relationships was part of a eight year behavioural study of S. vetulus nestor at Panadura and Piliyandala from 1985 to 1992, followed by periodic observations of monkey-human conflicts and habitat change from 19922006 at two study sites in Panadura and Piliyandala. Initially seven sites were surveyed (in seven villages) in and around Panadura, a coastal town approximately $16 \mathrm{~km}$ south of Colombo, and in Piliyandala, located inland on the banks of the Bolgoda River (a tributary of the Kalu Ganga). All surveyed sites (Figure 1) and their environs were completely devoid of natural vegetation, which is tropical wet evergreen rainforest (Gunatilleke $\&$ Gunatilleke, 1985). The land use at these sites were mapped in 1985 using 1:9500 aerial photographs (dated 1982) obtained from the Survey Department. The main land uses in these sites when the study commenced were home gardens and rubber monocultures, interspersed with patches of monoculture coconut cultivations.

Due to logistical reasons, the detailed study of monkey-human relationships was limited to two sites in Walapola-Etambagoda (at Panadura), and around the Regidale Estate in Kahapola (at Piliyandala) where an in-depth systematic behavioural study was carried out from 1985-1987 on two langur groups, namely: PT1 group at Panadura and R1 group at Piliyandala. The two main study sites exemplified scenarios representative of main land use types (i.e. home gardens and rubber monoculture) in the lowland wet zone inhabited by $S$. vetulus nestor. 
All seven sites surveyed were located at elevations below $100 \mathrm{~m}$ and had a relatively flat terrain. Rainfall and temperature data were obtained from the Department of Meteorology. The two main study sites at Panadura and Piliyandala had a mean daily temperature of $27.6{ }^{\circ} \mathrm{C}$ and a mean annual rainfall of $2290 \mathrm{~mm}$ and $2269 \mathrm{~mm}$ respectively. Both sites had cultivated and naturally propagated human edible fruit species (cultivars) and a similar number of trees per unit area (402/ha at Panadura and 411/ha at Piliyandala). Despite these similarities, land use patterns and vegetation differed between these two sites (Dela, 1998, 2007) Vegetation sampling in contiguous quadrats of $50 \mathrm{~m} \times 50 \mathrm{~m}$ showed that the Panadura site had a significantly higher tree species richness than the Piliyandala site (Dela, 2007). Almost all home garden areas at the Panadura site had been in existence for about 100 years, but those at Piliyandala had been established on land previously under rubber or scrub $<50$ years before the study began (Dela, 2007). Consequently, the Piliyandala site had fewer human edible fruit species $(\mathrm{N}=25)$ than at Panadura $(\mathrm{N}=32)$, and significantly lower biomass and fewer individuals per unit area of Artocarpus heterophyllus (jakfruit), than at Panadura (Dela, 2007). The Piliyandala site also had fewer mature individuals of Musa paradisiaca (banana) than at Panadura, and only one fruiting tree each of Artocarpus incisus (breadfruit) and Mangifera indica (mango) (Dela, 1998). The Piliyandala site had a marshy area with scrub vegetation between the home gardens and river, which was devoid of tall trees and not occupied by reproductive groups of $S$. vetulus nestor (i.e. groups with infants) during the systematic study, but there was fecal evidence of individuals in this area.

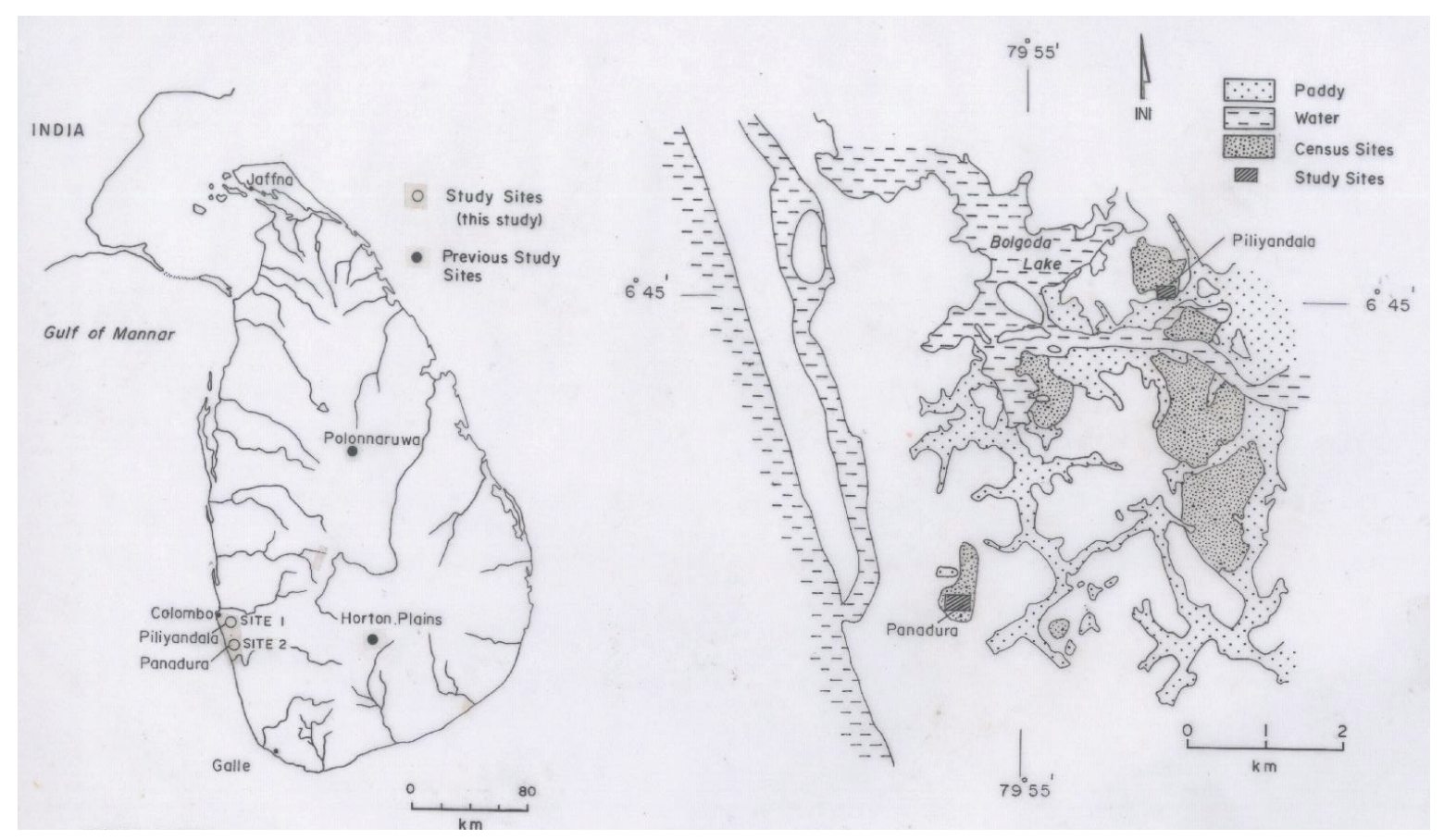

Figure 1: Location of seven census sites where monkey-human relationships were investigated in 1985

Data collection: Free-ranging reproductive groups of S.vetulus nestor were censused at seven villages (sites) in Panadura and Piliyandala (Figure 1) during a preliminary study spanning February 1985 - July 1985 at Panadura, and up to January 1986 at Piliyandala. At each site information was collected on the nature of monkeyhuman conflicts (i.e. harassment of monkeys, hunting, and cause of conflicts) through informal discussions with local people. Two groups were subsequently selected, followed and habituated prior to commencing a detailed study of behaviour. A vegetation survey of trees $\geq 30 \mathrm{~cm}$ gbh was carried out in the areas that the two selected monkey groups were seen to enter during the systematic study by sampling contiguous $50 \mathrm{~m} \mathrm{x}$ $50 \mathrm{~m}$ quadrats. Habituation was carried out by wearing green clothing and following a group during continuous 
five full-day periods interspersed with opportunistic encounters. During these interactions the observer followed the groups and remained clearly visible to the monkeys. This was followed by a systematic study of behaviour in the two habituated groups: PT1 group at Panadura (in Walapola-Etambagoda) from August 1985 - February 1987, R1 group at Piliyandala (at Kahapola) from February 1986 - February 1987, during consecutive monthly five-day sample periods. On each day, all interactions observed between the study groups and humans were recorded from $0600 \mathrm{~h}$ until light failed at dusk, with a break from $1220-1340 \mathrm{~h}$. during the preliminary study to reduce impact of the presence of the observer on householders interacting with monkeys in their gardens, they were specifically told that although the observer could not interfere with crop raiding, the householders were free to take any action they normally would. While some interactions may have been inhibited by the presence of the researcher, this was offset by the fact that some householders became aware of monkeys in their gardens only when they saw the researcher.

The monkey-human interactions recorded comprised provisioning by humans and any form of conflict or interaction between monkeys and humans. For the purpose of quantification, a conflict was defined as an incident involving physical injury or any other form of harassment of monkeys by humans. A conflict was considered to be terminated: (i) when all individuals in the monkey group were driven off, or had left a particular home garden or source of dispute (as relevant); (ii) if the cause of conflict was food, when all monkeys in the group had stopped feeding on the disputed food source, or had commenced another activity except resting, or (iii) when the house-holders ceased harassment, moved off and did not resume the conflict (harassment) before one hour had elapsed.

During the systematic study, all methods used by householders to prevent crop raiding by monkeys and verified reports of langurs hunted for food or as agricultural pests-in the study groups or in neighbouring groups-were recorded. It is recognized, however, that precautions taken to minimise the possibility of PT1 and $\mathrm{R} 1$ groups being decimated by hunters may have lowered the incidence of hunting with regard to these groups during the systematic study.

At the end of the systematic study in 1987, a questionnaire survey was carried out in all home gardens with houses ( $\mathrm{N}=94$ at Panadura, and $\mathrm{N}=18$ at Piliyandala) that were entered respectively by groups R1 and PT1 during the monthly sample periods. The questionnaire was prepared by the researcher and administered by two field assistants trained by the researcher, who were from the respective areas. This served to facilitate free expression of views by householders. The questionnaire elicited information on:

(i) the human environment (i.e., home garden size, number of houses per home garden, etc.) and the attitudes of local people towards langurs,

(ii) crop and habitat damage by monkeys, crop protection measures used by humans, and

(ii) envisaged changes in land use, that could lead to habitat alteration in the future.

At both sites habitat alteration by humans that occurred during the systematic study such as tree felling, land clearing for construction of houses, and fragmentation of home gardens for sale of land or for division among offspring were recorded monthly. Thereafter, monitoring was continued periodically up to November 2006. Discussions were held with randomly selected householders at both sites in 2006 regarding the population status of monkeys at the two sites.

During the systematic study, the Panadura (PT1) group ranged in size from 13 to 16 individuals, and the Piliyandala (R1) group ranged from 12 to14. Although most $S$. vetulus nestor groups were typically uni-male, both study groups had two adult males when first sighted, of which one was clearly the dominant male (Dela, 1998). Both groups underwent major changes in structure and composition at the end of the systematic study period due to Adult Male Replacement (AMR), a characteristic behaviour of this species by which the dominant adult male of a group is replaced by a new adult male (Rudran, 1973; Dela, 1998). The maximum home range size of groups PT1 and R1 during the systematic study were 9.6 ha and 3.9 ha, respectively (Dela, 1998).

Data analysis: The responses to the questionnaire survey in 1987 are presented as percentages of the total number of respondents to a respective question. All references to the specific number of conflicts reflect their frequency and not their duration. The Chi-square goodness-offit test was used to determine relationships for the data presented in this paper.

\section{RESULTS}

\section{The human environment at the main study sites}

The sites where $S$. vetulus nestor groups were censused comprised human modified areas (Figures 2 and 3) where monkeys co-occurred with humans. The study site occupied by PT1 group was located at the periphery of urban council limits of Panadura. During the systematic 
study, this site had home gardens and one patch of rubber of 0.25 ha. Almost all houses were permanent structures with brick walls and tiled or asbestos roofs. The questionnaire survey revealed that most houses had electricity and piped water. None of the home gardens had vegetable plots, but most contained a variety of naturally propagated or cultivated fruit trees. None of the households depended on agriculture for their livelihood. Most heads of households (males) were wage earners who traveled away from their village for work. About $97 \%$ of households were Sinhala Buddhists. A few households were related, but there was considerable socio-economic heterogeneity among households. This study site was within walking distance to the town centre, the hospital, and several large schools (Maha Vidyalayas).

The Piliyandala site was more rural and agricultural, and rubber monoculture was a prominent land use interspersed with home gardens. R1 group occupied part of a well-maintained rubber plantation of about 32 ha fringed by a few home gardens. About $61 \%$ of houses within the area ranged by R1 group were temporary structures with cadjan roofs and wattle and daub walls, and 39\% lacked lavatories. All households were Sinhala Buddhist and related, though economic levels of households differed. Almost all the adult males in these households were self-employed. Most households cultivated their own vegetables or purchased locally grown vegetables. Most households depended on agriculture for at least part of their income. Arecanut fruit and jakfruit were widely used for household consumption and sale. There was low interest in education among children of school going age, and the educational facilities in the village school were reportedly very poor.

Table 1 summarizes data on the human environment in the areas (referred to hereafter as the Panadura and Piliyandala sites) that were ranged by the two study groups. At both sites, significantly more households had an income $<$ Rs 2000/= per month in 1987 than above this income level (Panadura: $x^{2}=26.38, \mathrm{df}=1, \mathrm{p}<.01$; Piliyandala: $\left.x^{2}=12.25, \mathrm{df}=1, \mathrm{p}<.01\right)$. Most home gardens at both sites were $\leq 40$ perches ( $c a .0 .10$ ha). However, $40 \%$ of gardens at Panadura were $\leq 20$ perches $(<0.05$ ha), while only $28 \%$ of gardens at Pliyandala belonged to this category. Significantly more home gardens at both sites were $\leq 80$ perches ( $c a .0 .20 \mathrm{ha}$ ) than above this limit (Panadura: $x^{2}=55.68, \mathrm{df}=1, \mathrm{p}<.01$; Piliyandala: $x^{2}=5.55$, $\mathrm{df}=1, \mathrm{p}<.05)$. The Panadura site had home gardens with a density of 12 houses/ha. The more rural Piliyandala site had a much lower density of 3 houses/ha. This was due to the presence of several $(\mathrm{N}=5)$ large blocks of land that had no houses and the presence of rubber plantations devoid of houses. Most home gardens at both sites (irrespective of size) contained only one house, and only $24.7 \%$ and $11.8 \%$ of home gardens at Panadura and Piliyandala had two or three houses. All houses at the Piliyandala site and $86.8 \%$ houses at the Panadura site were self-owned.

Table 2 provides a summary of attitudes among local people towards monkeys at the end of the systemic study in 1987. At the more rural Piliyandala site, where many people depended on home garden produce for food or cash income, significantly more people $(82.4 \%)$ considered monkeys as pests than those who $\operatorname{did} \operatorname{not}\left(x^{2}=7.11, \mathrm{df}=1\right.$, $\mathrm{p}<.01)$. In contrast, there was no significant difference between these response categories $(47.5 \%$ and $53 \%$ respectively) at the more urban Panadura site $\left(x^{2}=.27\right.$, $\mathrm{df}=1)$. Nonetheless, at each site significantly more people did not want monkeys destroyed than those who did so (Panadura: $x^{2}=60.48, \mathrm{df}=1, \mathrm{p}<.01$; Piliyandala: $\left.x^{2}=13.24, \mathrm{df}=1, \mathrm{p}<.01\right)$. Less than $10 \%$ of the households at each site wanted monkeys destroyed, and only $2.2 \%$ of households at Panadura and none at Piliyandala were willing to do so themselves. None of the households at both sites felt that monkeys should be used as a cheap

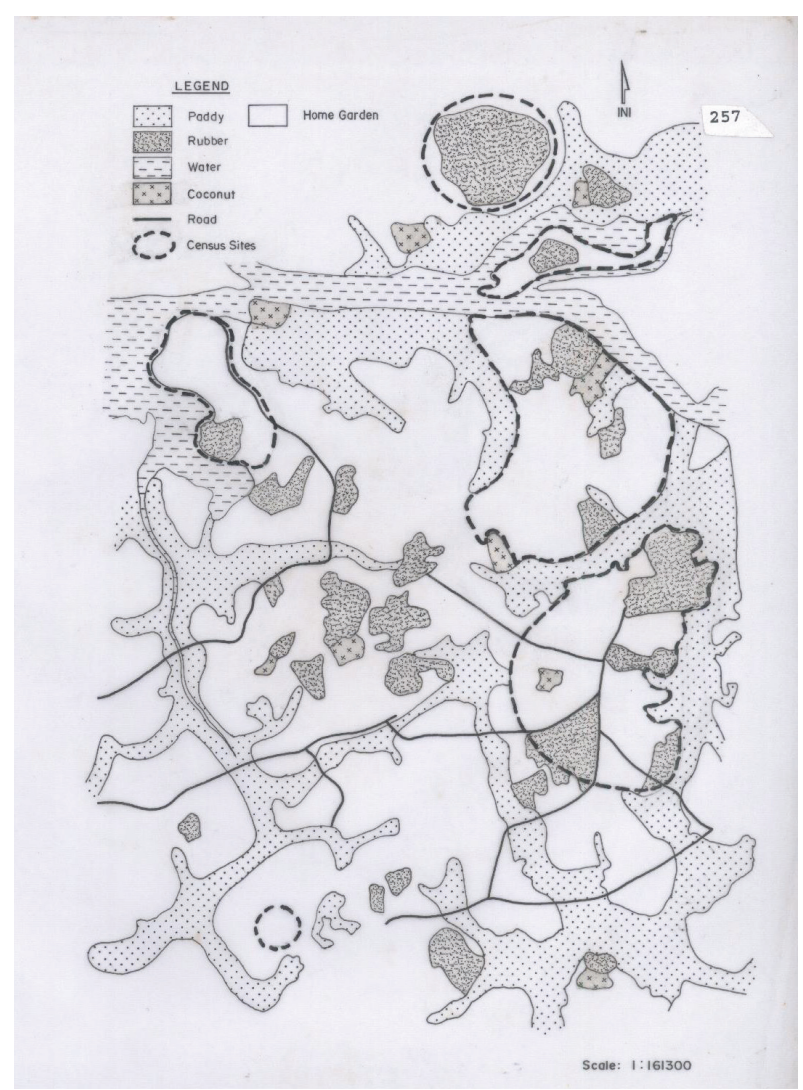

Figure 2: Land use patterns at six census in 1985 excluding the Panadura site 
source of protein. At the more rural Piliyandala site, where all householders were Buddhists, $76.5 \%$ felt that monkeys should not be destroyed mainly due to religious reasons; only $17.7 \%$ felt that monkeys should be protected mainly because they were a valuable part of the environment. In contrast, at Panadura, where almost
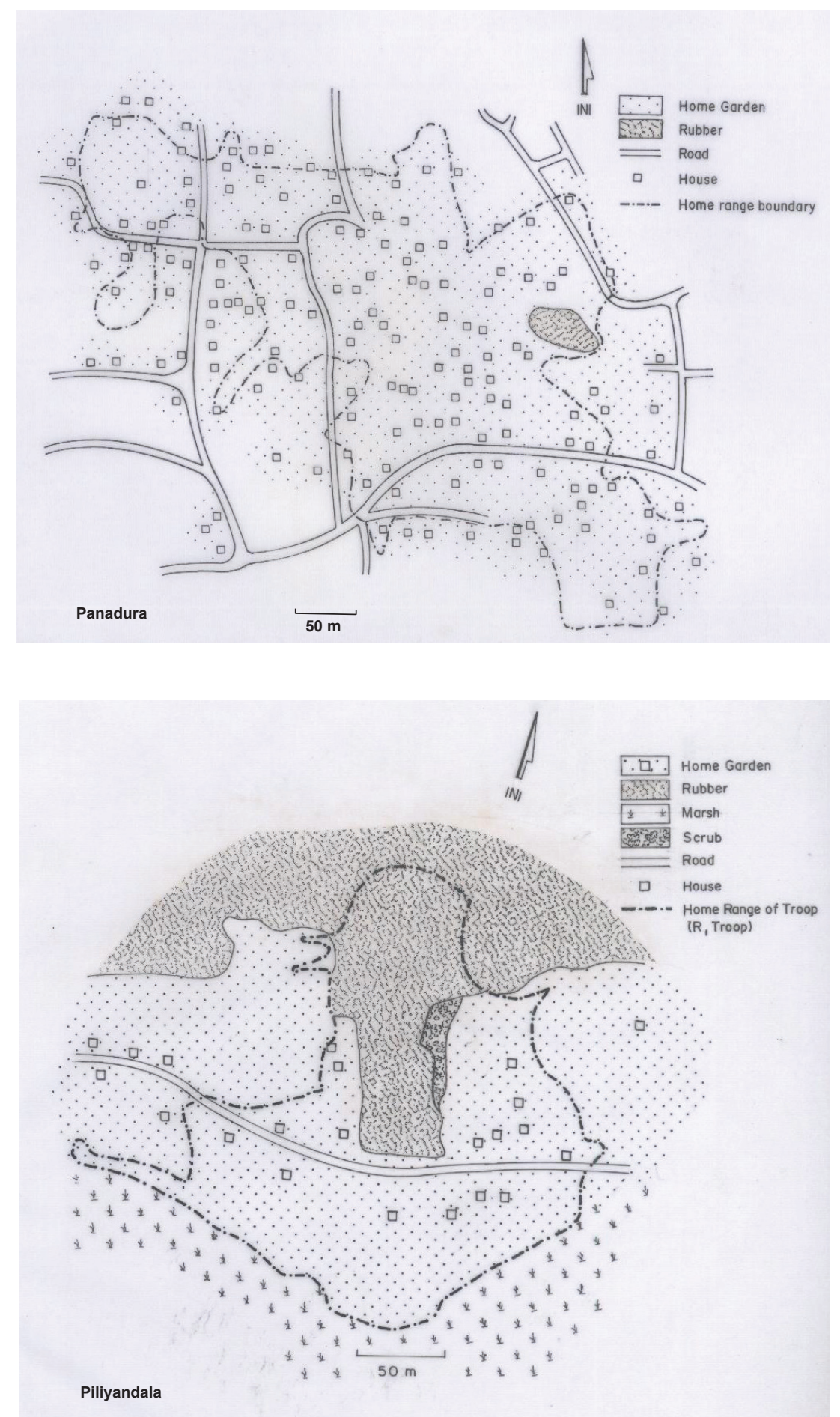

Figure 3: Sketch maps of land use patterns in the areas ranges by PT1 group and R1 group during the systematic study (1985-1987) 
all households were Buddhists, and people had access to a good education, $52.7 \%$ of households felt that monkeys should be protected mainly because they were a valuable part of the environment, while only $37.6 \%$ felt that monkeys should not be destroyed mainly due to religious reasons.

Table 3 shows that despite considerable tolerance of monkeys at both sites, few people welcomed their presence. Combined data from both sites show that significantly more households chased them than households that ignored them or enjoyed watching them $\left(\mathrm{x}^{2}=116.3, \mathrm{df}=1, \mathrm{p}<.01\right)$. Most people at both sites, however, harassed monkeys only if they caused damage. There were also seven reports from the Panadura site (between 1985 - 2006) and one from Piliyandala (1987) of local people tending injured monkeys. There were no reports in or near the Panadura site of injured monkeys being killed by householders. In contrast, there were two verified reports at Piliyandala $(1986$ - 1987) of injured monkeys that fell to the ground being killed for food by local hunters.

The PT1 group was provisioned by $10.6 \%$ of households $(\mathrm{N}=10 / 94)$ during the systematic study, but this is negligible as it comprised only $1 \%$ of the total diet (Dela, in press). Upon entering a garden where the group was provisioned, the adult male of the group was in the habit of soliciting provisioning by giving a contact call (gaw call) and peering towards the house from a

Table 1: Socio-economic characteristics of the human environment at the two main study sites in 1987a

\begin{tabular}{lcc}
\hline & $\begin{array}{c}\text { Panadura site } \\
\%\end{array}$ & $\begin{array}{c}\text { Piliyandala site } \\
\%\end{array}$ \\
& $\begin{array}{c}\text { (number of responses/ } \\
\text { total responses) }\end{array}$ & $\begin{array}{c}\text { (number of responses/ } \\
\text { total responses) }\end{array}$ \\
\hline $\begin{array}{l}\text { Households with cash } \\
\text { incomes }>\text { Rs 2000/ per month }\end{array}$ & $23.1(21 / 91)$ & $6.3(1 / 16)$ \\
$\begin{array}{l}\text { Households with cash } \\
\text { incomes }<\text { Rs } 2000 / \text { per month } \\
\text { Home Gardens }>80 \text { perches }\end{array}$ & $76.9(70 / 91)$ & $93.8(15 / 16)$ \\
Home gardens $\leq 40$ perches & $10.2(9 / 88)$ & $22.2(4 / 18)$ \\
Home gardens with one house only & $75 \%(66 / 88)$ & $72.2(13 / 18)$ \\
\hline
\end{tabular}

${ }^{a}$ response to questionnaire

Table 2: Householders' attitudes towards monkeys at the two main study sites in 1987a

\begin{tabular}{lcc}
\hline & \multicolumn{2}{c}{$\%$ HH selecting response } \\
& Panadura site & $\begin{array}{c}\text { Piliyandala site } \\
(\mathrm{N}=17)\end{array}$ \\
Responses & $(\mathrm{N}=93)$ & $82.4(\mathrm{~N}=14)$ \\
Monkeys are pests & $47.3(\mathrm{~N}=44)$ & $5.9(\mathrm{~N}=1)$ \\
$\begin{array}{l}\text { Monkeys should be destroyed } \\
\text { Monkeys are a pest but should not be destroyed due to }\end{array}$ & $9.7(\mathrm{~N}=9)$ & $76.5(\mathrm{~N}=13)$ \\
$\begin{array}{l}\text { religious reasons } \\
\text { Monkeys should be protected as a valuable part of the }\end{array}$ & $52.7(\mathrm{~N}=45)$ & $17.7(\mathrm{~N}=3)$ \\
$\begin{array}{l}\text { environment } \\
\text { Monkeys should be utilized as a cheap source of protein }\end{array}$ & None & None \\
\hline
\end{tabular}

${ }^{a}$ response to questionnaire. 
nearby tree until a food item was provided. Bread and coconut kernel were the most frequently provided foods. Provisioning monkeys was not recorded at any of the other six sites that were investigated. Food snatching from humans was never observed or reported at these sites, but there were two reports of food pilfering from a house by the adult male of the PT1 group. One of these households provisioned monkeys.

\section{Food competition}

Crop and roof damage were the most frequently cited damage from $S$. vetulus nestor at all 7 villages surveyed in 1985. During the systematic study, both study groups used human edible plant items as food. PT1 group used twenty-six plant species for human edible fruit and seeds, four for leaves, and one for stems (vine), compared with R1 group's use of 13 species for human edible fruit and seeds, two for leaves and one for yams. These species yielding human edible plant parts comprised respectively about $25 \%$ of all plant species used by PT1 group $(\mathrm{N}=115)$ and $\mathrm{R} 1$ group $(\mathrm{N}=59)$.

In terms of monkey-human conflicts, food conflicts were more frequent than other conflicts for both PT1 and R1 groups (Table 4), and this difference was significant (Panadura: $x^{2}=14.78, \mathrm{df}=1, \mathrm{p}<.01$ : Piliyandala: $x^{2}=4.54$, $\mathrm{df}=1, \mathrm{p}<.05)$. At Panadura, most food conflicts arose when monkeys fed on fruits of Mangifera indica (mango), Musa paradisiaca (banana) and Artocarpus incisus (bread fruit) that were dominant species in the vegetation. The availability of harvest mature fruits of these species for the langurs was severely curtailed by human harvesting and stringent crop protection measures. There was relatively low conflict over Artocarpus heterophyllus fruit at Panadura where there was a surplus on the trees for household consumption. In contrast, most food conflicts occurred at the more rural Piliyandala site when langurs fed on A. heterophyllus fruit (Table 4), which was frequently used by many households for both consumption and sale. There were fewer conflicts over fruits of $M$. indica and $A$. incisus at Piliyandala as there was only one fruiting tree each of these species, and most $M$. paradisiaca at this site were young plants with no fruits. There was a higher frequency of conflicts per day between PT1 group and householders (0.71/day) at the more densely populated Panadura site, than between R1 group and householders (0.41/day) at the Piliyandala site (Table 4).

\section{Roof damage}

Only $9.2 \%$ and $4.5 \%$ of conflicts directly observed at Panadura and Piliyandala respectively were connected with roof damage (Table 4), although monkeys caused damage to crops and tiled roofs at both study sites (Table 5). Roof damage occurred when monkeys moved across tiled roofs to bridge gaps in arboreal pathways, or more infrequently when they chased each other very vigorously during inter-group fights connected with adult male replacement (AMR). However, at Panadura, where most houses had permanent tiled roofs in 1987, significantly more households prioritized roof damage over crop damage as the most serious financial loss caused by monkeys $\left(x^{2}=28, \mathrm{df}=1, \mathrm{p}<.01\right)$. In contrast, at the more rural and agricultural Piliyandala site, where $61 \%$ of houses had thatched roofs in 1987 , more households prioritized crop damage over roof damage (Table 5), although this difference was not statistically significant $\left(x^{2}=0.25, \mathrm{df}=1\right)$. By 2006, however, most houses at both sites had asbestos roofing, which is less prone to monkey damage than tiled roofs. However, as these roofs too were sometimes damaged by monkeys, and the cost of replacement was higher than for tiled roofs, householders tended to remove large trees near houses to prevent monkeys moving on roofs.

Table 3: Householders' reaction to monkeys entering their home gardens at the two main study sites in 1987a

\begin{tabular}{|c|c|c|}
\hline \multirow[t]{2}{*}{ Responses } & \multicolumn{2}{|c|}{$\% \mathrm{HH}$ selecting response } \\
\hline & $\begin{array}{l}\text { Panadura Site } \\
\qquad(\mathrm{N}=92)\end{array}$ & $\begin{array}{l}\text { Piliyandala Site } \\
\qquad(\mathrm{N}=18)\end{array}$ \\
\hline Dislike it, but cannot be bothered to chase out monkeys & $8.7(\mathrm{~N}=8)$ & $11.1(\mathrm{~N}=2)$ \\
\hline Chase out monkeys at once & $19.6(\mathrm{~N}=18)$ & $22.2(\mathrm{~N}=4)$ \\
\hline Chase out monkeys only if they cause crop or roof damage & $63.1(\mathrm{~N}=58)$ & $55.6(\mathrm{~N}=10)$ \\
\hline Let the monkeys feed and enjoy watching them & $8.7(\mathrm{~N}=8)$ & $11.1(\mathrm{~N}=2)$ \\
\hline
\end{tabular}

${ }^{\text {a }}$ response to questionnaire. 
Table 4: Causes underlying monkey-human conflict with the PT1 and R1 groups during the systematic study (1985-1987)

\begin{tabular}{lcl}
\hline $\begin{array}{l}\text { Reasons for householders } \\
\text { chasing monkeys }\end{array}$ & $\begin{array}{c}\mathrm{PT}_{1} \text { group } \\
(92 \text { days })^{\mathrm{b}}\end{array}$ & $\begin{array}{l}\mathrm{R}_{1} \text { group } \\
(54 \text { days })^{\mathrm{b}}\end{array}$ \\
\hline No specific reason & $3(4.6 \%)$ & $1(4.5 \%)$ \\
Entering garden & $8(12.3 \%)$ & $4(18.2 \%)$ \\
Roof damage & $6(9.2 \%)$ & $1(4.5 \%)$ \\
Feeding on banana fruit & $17(26.2 \%)$ & $5(22.7 \%)$ \\
Feeding on bread fruit & $6(9.2 \%)$ & $1(4.5 \%)$ \\
Feeding on mango fruit & $7(10.8 \%)$ & $1(4.5 \%)$ \\
Feeding on jak fruit & $2(3.1 \%)$ & $6(27.3 \%)$ \\
Feeding on other human edible fruit & $14(21.5 \%)$ & $2(9.1 \%)$ \\
Feeding on murunga leaves & $1(1.5 \%)$ & 0 \\
Feeding on papaw fruit and leaves & $1(1.5 \%)$ & $1(4.5 \%)$ \\
Total observed food conflicts & $48(73.8 \%)$ & $16(72.7 \%)$ \\
All conflicts observed during the & 65 & 22 \\
monthly sample periods ${ }^{\mathrm{a}}$ & & \\
Average number of conflicts per day & 0.71 & 0.41
\end{tabular}

a Cause of conflict stated as a percentage of all conflicts at each of the two study sites from direct observations during monthly sample periods spanning 19 months at Panadura and 13 months at Piliyandala.

Table 5: Householders' perception of the most serious economic damage caused by monkeys at the two main study sites in $1987^{\text {a }}$

\begin{tabular}{|c|c|c|}
\hline \multirow[b]{2}{*}{ Responses } & \multicolumn{2}{|c|}{$\begin{array}{c}\% \mathrm{HH} \\
\text { selecting response }\end{array}$} \\
\hline & $\begin{array}{l}\text { Panadura Site } \\
\qquad(\mathrm{N}=91)\end{array}$ & $\begin{array}{c}\text { Piliyandala Site } \\
\qquad(\mathrm{N}=18)\end{array}$ \\
\hline Roof damage & $71.4(\mathrm{~N}=65)$ & $38.9(\mathrm{~N}=7)$ \\
\hline Crop damage & $18.7(\mathrm{~N}=17)$ & $50 \%(\mathrm{~N}=9)$ \\
\hline No serious loss & $9.9(\mathrm{~N}=9)$ & $11.1(\mathrm{~N}=2)$ \\
\hline
\end{tabular}

${ }^{\text {a }}$ response to questionnaire

\section{Crop protection measures used by householders}

Householders at both study sites found it difficult to prevent monkeys feeding on crops, although they employed a variety of crop protection methods centered on loud noises, throwing projectiles, visual methods and shooting (Table 6). Only one household cited shooting monkeys as a crop protection method. This was also not very effective, as in all four cases of shooting that occurred at the Panadura site (Table 7), langurs revisited the area soon after the incident. Further, adult male replacement (AMR) which followed the shooting of the adult male in the PT1 group in 1987 caused other groups to invade the area, and brought about frequent inter-group fights that were very damaging to the vegetation and tiled roofs for a period of one year. Most householders at both sites $(66.7 \%)$ used loud noises, such as crackers, to prevent crop damage, while $27.9 \%$ threw stones or used slingshots (i.e. catapults). The use of slingshots, though fairly effective to prevent crop raiding, rarely caused physical injury to the langurs. More harmful methods such as poisoning and sticking jak fruits with needles were mentioned at the other surveyed sites during the census survey, but could not be verified due to the brevity of the initial survey. Some householders also used feeding deterrents such as encasing unripe banana fruits with a polythene cover or application of fresh cow-dung on the banana fruits. Such deterrents were considered more effective than detection and driving off by using loud noises, throwing projectiles or visual methods.

A very few householders at the Panadura and Piliyandala sites (15.3\%) did not use any crop protection method. Most householders in this category at Panadura were living on rent and had no claim to garden produce, but a few refrained from chasing monkeys due to extreme tolerance as they enjoyed watching monkeys (Table 3 ). All households at the Piliyandala site that did not use preventive methods had no fruit trees to protect from monkeys.

\section{Hunting}

Hunting of langurs varied in intensity at the seven sites surveyed during this study. At one site (Malamulla, Panadura), local people admitted that the langur population had dropped due to hunting. This was corroborated by the fact that the census revealed few langur groups in this area, and it was very difficult to get group counts as individuals tended to stay hidden more than at other sites. The reasons for hunting at the seven sites varied from obtaining flesh considered a delicacy, obtaining meat to consume with illicit liquor, or for crop protection. Methods used for hunting included using a shot gun, clubbing to death, or dashing against a stone or tree when captured on the ground.

Verified reliable reports of langurs hunted in the two study groups and adjacent groups during 1985-1987 are given (Table 7). Hunting was inhibited at the main study sites due to interventions by the researcher, necessitated after two monkeys from the PT1 group were shot by a single householder within two months of the behavioural study. The adult male in the PT1 group was shot for crop protection by a householder immediately after the systematic study ended. This caused the group to break 
Table 6: Percentage of responses according to crop protection methods used at both study sites in Panadura and Piliyandala ${ }^{\mathrm{a}}$

\begin{tabular}{|c|c|}
\hline Methods & $\begin{array}{l}\text { \% HH selecting response } \\
(\mathrm{N}=111) \text { respondents } \\
\text { (more than one method was } \\
\text { listed by respondents) }\end{array}$ \\
\hline \multicolumn{2}{|l|}{ Loud noises } \\
\hline (Lighting fire crackers, using a gong, shouting) & $66.7(\mathrm{~N}=74)$ \\
\hline \multicolumn{2}{|l|}{ Throwing projectiles } \\
\hline (Throwing stones, using a slingshot or catapult) & $27.9(\mathrm{~N}=31)$ \\
\hline \multicolumn{2}{|l|}{ Visual methods including showing a gun } \\
\hline (Showing a gun but not shooting, flashing a mirror) & $3.6(\mathrm{~N}=4)$ \\
\hline Shooting & $0.9(\mathrm{~N}=1)$ \\
\hline No methods used & $15.3(\mathrm{~N}=17)$ \\
\hline
\end{tabular}

${ }^{\text {a }}$ Several methods were used by some households

Table 7: Verified reports of monkeys hunted in and around the two main study sites during 1985-1987

\begin{tabular}{|c|c|c|}
\hline Troop & Age / Sex & Remarks \\
\hline PT1 & Adult male & $\begin{array}{l}\text { Shot by } \mathrm{HH} \text { for food } \\
\text { (February } 1985 \text {, during the preliminary survey) }\end{array}$ \\
\hline PT1 & Adult female & $\begin{array}{l}\text { Shot by same HH for food and injured in August } 1985 \\
\text { Died from fall due to injury }\end{array}$ \\
\hline PT1 & Sub-adult female & Short by same HH for food in October 1985 \\
\hline PT1 & Adult male & Shot by HH for crop damage in March 1987 \\
\hline R1 & Adult female & Shot for food by poachers in September 1985 \\
\hline R1 & Adult female & $\begin{array}{l}\text { Captured and killed for food when moving on the ground } \\
\text { during an inter-groups fight during adult male replacement } \\
\text { in March } 1987\end{array}$ \\
\hline R3 group & $\begin{array}{l}\text { Three individuals, } \\
\text { age/sex unknown }\end{array}$ & Reported as killed for food \\
\hline
\end{tabular}

PT1 group at Panadura; R1 and R3 groups at Piliyandala.

up, and the infants and juveniles were subject to attack and eviction by invading males during the AMR that ensued.

At both sites very few householders destroyed monkeys. Nonetheless, nine monkeys were killed by hunters in and around the home ranges of the two study groups during 24 months, even though most householders eschewed this practice and held hunters in low esteem. At Panadura these sentiments were expressed openly. In contrast, there was no public censure of hunting at Piliyandala where poachers were from the same community, heavy consumers of liquor, and the most aggressive persons in the village. At both sites householders did not permit strangers to the area to poach in their gardens.

This study showed no relationship between poverty and hunting (Table 8). Combined data for both sites showed that significantly more households with a monthly income $<$ Rs 2000/- (in 1987) did not want to destroy monkeys than those who wanted to do so $\left(x^{2}=62.23, \mathrm{df}=1, \mathrm{p}<.01\right)$. Although the hunters at Piliyandala were those with a monthly income $<$ Rs $2000 /-$, 
Table 8: Tolerance of monkeys by income category at both study sites

Attitude categories
$\begin{gathered}\text { <Rs 2000/= } \\ (\mathrm{N}=81)\end{gathered}$

the two householders who shot monkeys in their home gardens at the Panadura site had licensed guns and were of a higher socio-economic and educational level than their neighbours.

\section{Other threats to langurs in human modified areas}

At both sites, predation of langurs by domestic dogs was rare in 1987. Only two cases of predation by dogs were reported from 1985-1987, and one case of fatal injury since then up to 2006. There were no other nonhuman predators of monkeys at both sites. Live capture of langurs by householders at all surveyed sites was confined to infants abandoned by their mothers after AMR in reproductive groups, or infants that were sick or badly injured. Captured infants were reared as household pets. There were no reports of trapping for commercial purposes in any of the seven villages surveyed. Although captives encountered during the study were reared with affection by their human captors, their maintenance was unsatisfactory, as they were kept tethered and fed on a diet high in rice and bread. One captive encountered during the 2008-2010 survey consumed eggs and flesh. One partially blind male juvenile of 12 months (discarded by PT1 group in 1986) and a seven month female infant abandoned after AMR in the same group (in March 1987), were reared by the researcher until 1992, and provided with their natural diet. The female joined a freeranging group at 6 years of age and remained free until she succumbed to an injury, caused by a fall, at nearly 20 years of age in June 2006.

Langurs often traveled on power lines to bridge gaps in the canopy. This sometimes resulted in death or serious injury due to electrocution. Four animals from R2 group at the Piliyandala site died due to electrocution in June 1986, when power was first supplied to this area. As the power lines had been installed many months previously, the monkeys were used to moving on them. One juvenile female from an adjoining group at the Panadura site died due to electrocution. The use of power lines by the langurs for travel increased in and around the Panadura site between 1987-2006. No individuals with badly mutilated limbs were observed in reproductive groups during the 1985 - 1987 censuses. In contrast, three animals with mutilated limbs and tails (one effect of electrocution confirmed, two suggestive of electrocution) were seen in reproductive groups ranging within the main Panadura study site from 2002-2006; two more have been sighted since then, and one animal died due to dog attack after falling to the ground due to electrocution.

\section{Habitat change}

Effects of habitat alteration at the two sites were investigated in terms of: (i) loss of home range area and arboreal paths, (ii) loss of important food trees, and (iii) loss of important sleeping trees. One year after the study commenced in 1985,101 trees $\geq 30 \mathrm{~cm}$ gbh had been felled at the Panadura site. This included several of the largest Artocarpus heterophyllus (jak trees) to be sold for timber. The household survey in 1987 indicated that $48.2 \%$ of households at the Panadura site and $29.4 \%$ at the Piliyandala site did not envisage habitat alteration by way of tree felling, sale of land, division of home gardens among family members, building more houses, and felling and sale of valuable timber species (Table 9). Observations at Panadura in 2006 showed, however, that almost all home gardens that existed in 1987 were severely fragmented either for division among family members to construct houses or due to sale of land. An increase in the density of houses at Panadura (from 12/ha in 1987) had caused a considerable loss of canopy cover due to land clearing for housing and felling of $A$. heterophyllus

Table 9: Householders' responses in 1987 on envisaged future changes in home gardens at the two main study sites. ${ }^{\text {a }}$

\begin{tabular}{llc}
\hline Responses & \% HH selecting response \\
& $\begin{array}{l}\text { Panadura Site } \\
(\mathrm{N}=83)\end{array}$ & $\begin{array}{c}\text { Piliyandala Site } \\
(\mathrm{N}=17)\end{array}$ \\
\hline $\begin{array}{l}\text { Sell it whole or partly } \\
\text { Divide among family members }\end{array}$ & $\begin{array}{l}7.2(6) \\
\text { Build more houses in it }\end{array}$ & $5.9(1)$ \\
Cut down valuable timber trees & $12.1(10)$ & $47.1(8)$ \\
for sale & $1.2(1)$ & - \\
Keep it as it is and grow more trees & $48.2(40)$ & $29.4(5)$ \\
\hline
\end{tabular}

${ }^{a}$ response to questionnaire. 
for timber. Discussions with householders showed that home garden fragmentation at Panadura was influenced by about a 50 fold increase in land values between 1985 and 2006. At the Piliyandala site, almost all of the 32 ha rubber plantation had been clear felled to build a factory and a luxury housing complex. The latter scheme had been abandoned by 2006 due to householder protests after the rubber trees were felled. Other major changes in home gardens at this site were mainly due to felling of trees during conversion of wattle and daub houses to permanent houses and building more permanent houses in the home gardens.

Figure 4 shows loss of home range area for the PT1 group from 1985 to 1992 . Area B was subject to heavy tree felling for sale of land (and subsequent housing construction) during July - August 1986, after which this area was abandoned by PT1 group. The destruction of several other important arboreal pathways for PT1 group during this period resulted in the loss of more home range area and important food trees. Four of the five most frequently used sleeping sites used by PT1 group during the systematic study were lost between 1985-1992 due to tree felling (Figure 5). By 2006, 22 out of all 28 sleeping sites used by PT1 group from 1985 to 1987 had been completely felled or severely degraded, while all other sleeping sites had been partially degraded due to tree felling. Similarly 16 out of the 20 sleeping sites used by R1 group during the systematic study were completely lost or severely degraded by 2006.

R1 group descended to the ground to cross the narrow dirt road bisecting its home range (Figure 3) during 1986-1987. In contrast, PT1 group never used ground crossings when arboreal paths were disrupted. Both groups came down to the ground to feed on rubber seeds and for play, but individuals never strayed away from tall trees to which they retreated when alarmed.

Tree felling between 1992 and 2006 had resulted in $>50-75 \%$ loss of tree cover in 8 of the 10 most frequently used vegetation quadrats used by PT1 group during the systematic study (Figure 5). Similarly, by 2006 there had been a $>50-100 \%$ loss of tree cover in 9 of the 10 most heavily used vegetation quadrats used by R1 group during the systematic study. This included a 100\% loss of rubber trees and an almost $100 \%$ loss of tall trees in the most heavily used area by R 1 group during the systematic study.

The top three food species used by PT1 group: A. heterophyllus, Tamarindus indica (tamarind) and Ceiba pentandra (kapok), as well as Hevea brasiliensis (rubber) were among the most affected species due to tree felling. Figure 6 shows the loss of fruiting C. pentandra and $T$. indica trees and the entire rubber holding within the area ranged by PT1 group from 1987-2006. By 2006 only one fruiting tree of $C$. pentandra and two fruiting trees of T. indica remained in this area. A complete record of the number of $A$. heterophyllus felled upto 2006 is not available, but the degradation of sleeping sites in home gardens at both sites was mainly due to the loss of large A. heterophyllus trees.

Discussions with local people at the Piliyandala site indicate that monkey populations had dropped considerably between 1985 and 2006. It was reported that some monkey groups had moved into scrub areas in the marshy lands abutting the river. Four out of five households questioned randomly expressed concern regarding the reduction of the langur population. A positive feature was the report that langurs were no longer hunted at this site due to socio-economic advancement of villagers.

\section{DISCUSSION}

The systematic and long-term study on the feeding behaviour of $S$. vetulus nestor showed that these langurs are well adapted to live in human modified areas with adequate canopy cover (Dela, 1998), where they have selectively adopted a high fruit diet (Dela, 2007, in press), unlike the predominantly folivorous forest populations of $S$. vetulus philbricki and $S$. vetulus monticola (Rudran, 1970). At the commencement of the systematic study in 1985, the area used by PT1 group (i.e. Etambagoda-Walapola) had a much higher density of human habitations compared with the more rural area occupied by R1 group. Both sites, however, had $>400$ trees/ha of individuals with a gbh $\geq 30 \mathrm{~cm}$ (Dela, 1998), which provided sufficient food resources for the langurs to consume a varied diet year-round, which was high in seasonal food items, mainly fruit (Dela, 2007). The survey in 2006 showed, however, that both study sites had undergone major changes resulting in a considerable loss of canopy cover, which had led to reduced availability of key food sources, sleeping trees and arboreal pathways for the langurs.

Although primates such as Macaca sinica (J.D.S. Dela, personal observation), Macaca mullata and Semnopithecus priam live successfully in villages, towns and cities with sparse tree cover (Eudey 1987; Southwick et al., 1965; Singh, 1969), some arboreal colobines are highly susceptible to changes in their food supply as exemplified by a one-third decline of the red colobus population in response to light tree felling (Davies, 


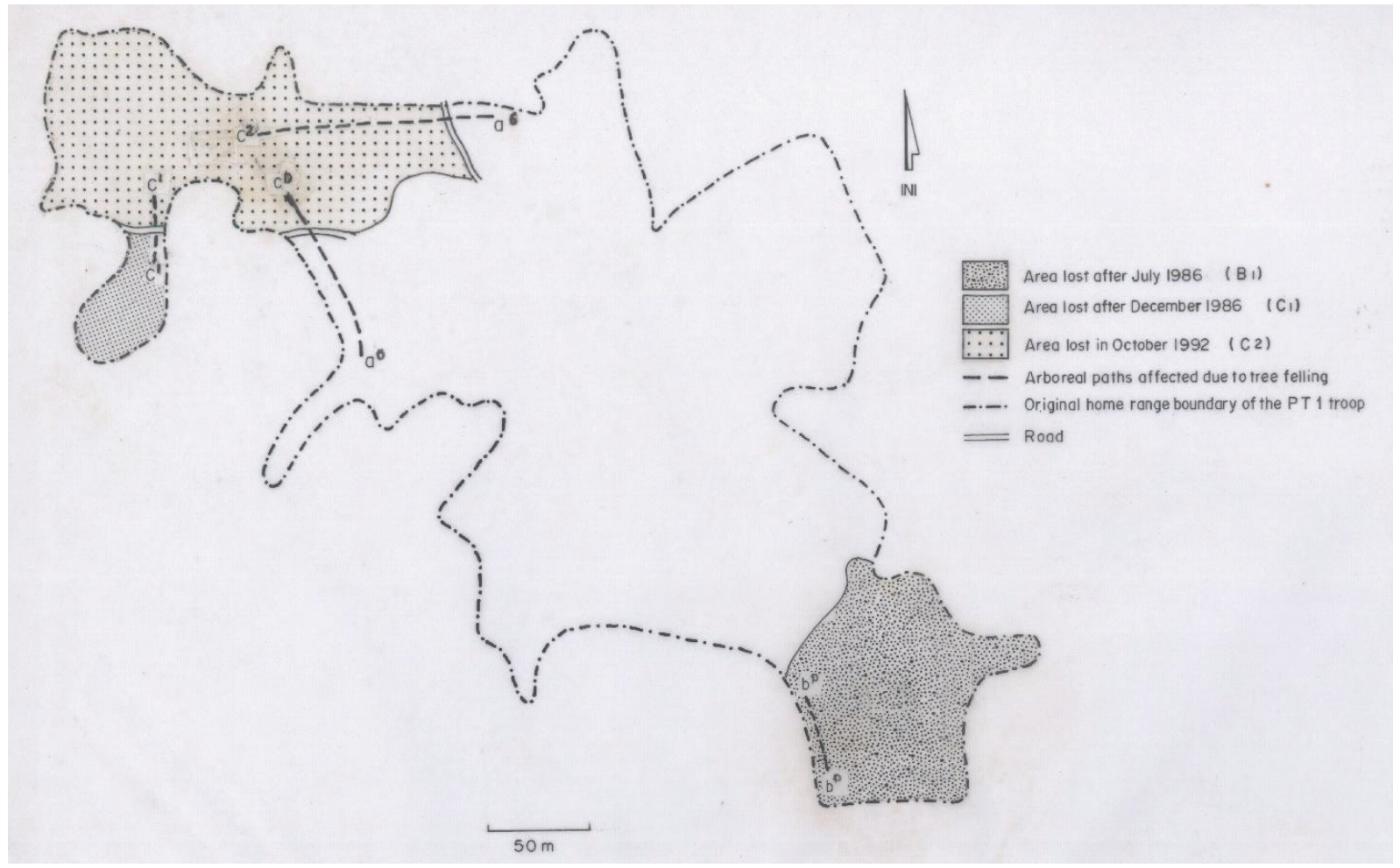

Figure 4: Sketch maps showing loss of PT1 group's home range area due to tree felling between 1985-1987

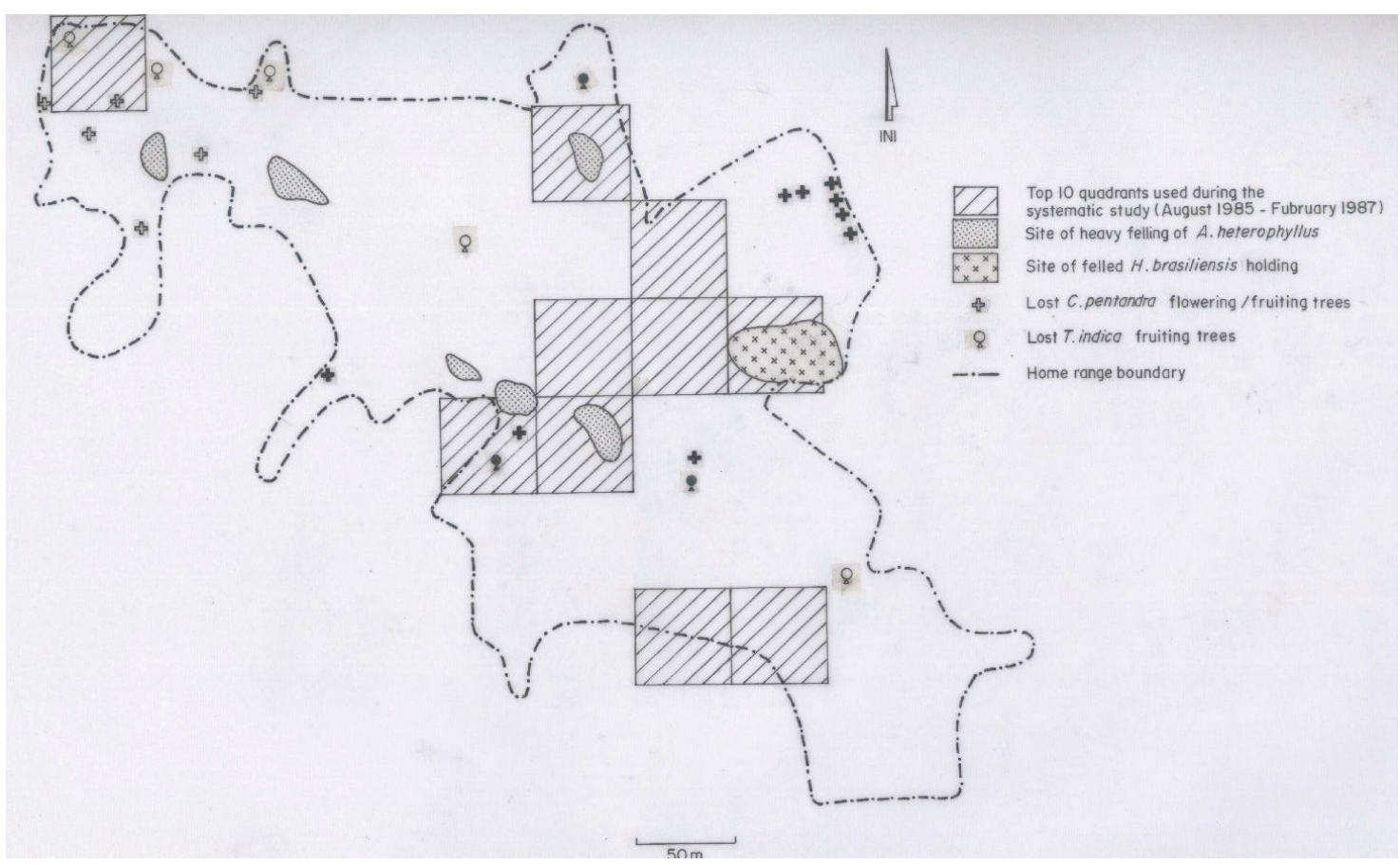

Figure 5: Sketch maps of the Panadura site indicating heavy tree felling between 1985-2006 in the top 10 vegetation quadrats visited by PT1 group 


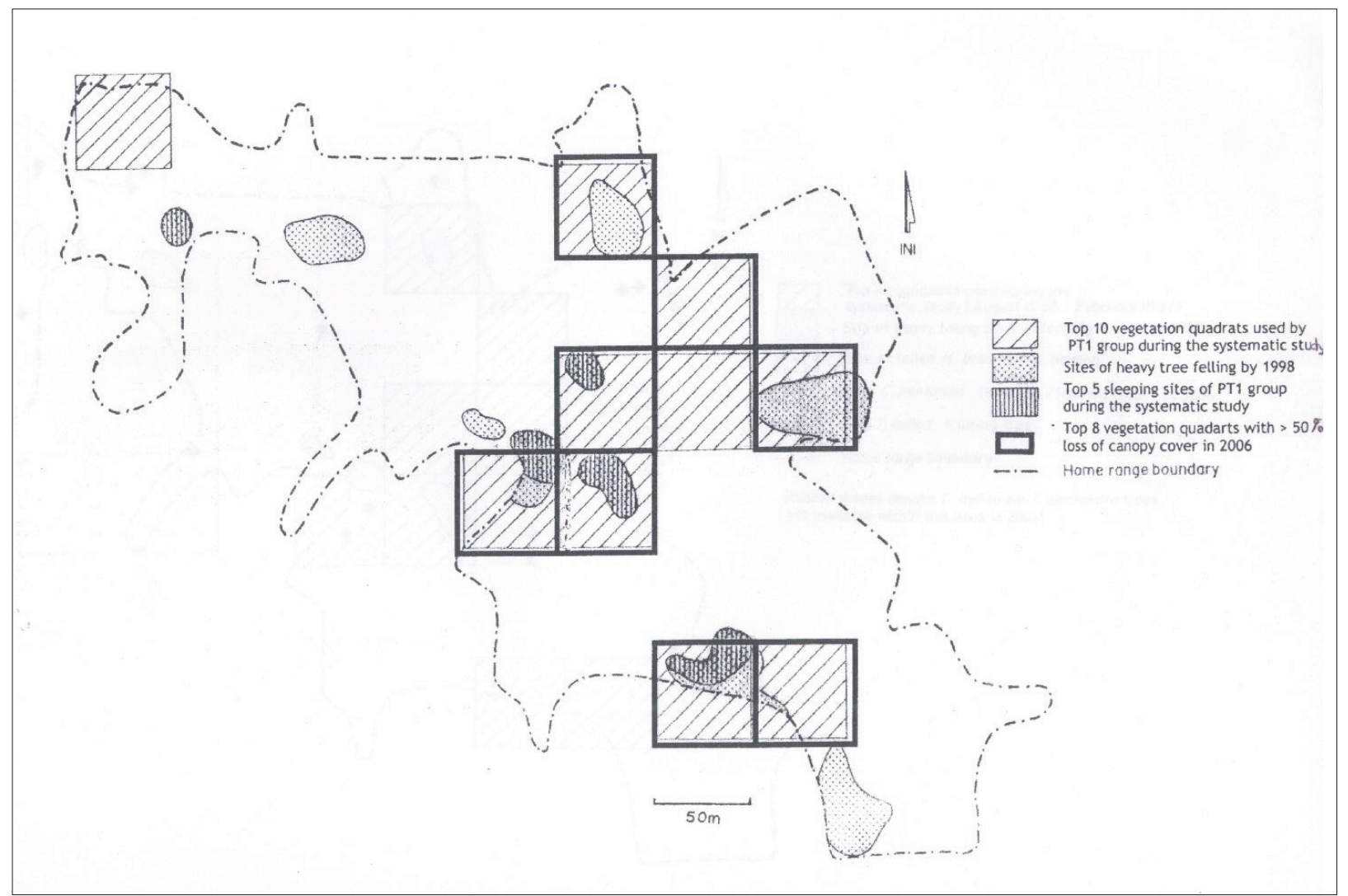

Figure 6: Loss of important food trees at the Panadura site (Walapola-Etambagoda) between 1987-2006

1994). The present study also demonstrates that tree felling results in a reduction of home range size, food trees and sleeping sites for $S$. vetulus nestor (Dela, 1998). For both study groups, use of different parts of their home ranges had a significantly positive relationship with tree species richness (ibid). However, almost all the 10 most heavily used vegetation quadrats by R1 and PT1 groups during the systematic study had been subject to severe tree felling between 1987 and 2006. This had served to greatly reduce the availability of food for langurs at the two study sites by 2006 (J.D.S.Dela, unpublished data). Furthermore, Artocarpus heterophyllus, which provided $28.2 \%$ of the diet of PT1 group (Dela, 2007), was one of the most affected species by tree felling at the Panadura site between 1985 to 2006 . Large reproductively mature $A$. heterophyllus trees that were selectively removed as timber, were the most important trees in terms of canopy cover, food and sleeping trees for the langurs (Dela, 1998). The loss of all Hevea brasiliensis trees, and all but one fruiting individual of Tamarindus indica and Ceiba pentandra, which provided $18.4 \%$ of the diet of PT1 group during the systematic study (Dela, 2007), exemplifies the reduction of food sources for langurs due to habitat change. Similarly, A. heterophyllus and $H$. brasiliensis provided $>65 \%$ of the diet for $\mathrm{R} 1$ group (ibid), while $H$. brasiliensis covered about $40 \%$ of the group's home range (Dela, 1998). As such, the loss of these top food species can be expected to severely affect the diet of langurs remaining at the Piliyandala site, and was probably the cause of the reported population decline of langurs at this site by 2006. By 2010 almost all of the former PT1 home range was devoid of monkeys, with the pocketing of one group in a section of the range (J.D.S.Dela, unpublished data). This could also be attributed to tree felling induced habitat change. Likewise, drastic population crashes for the red colobus have been recorded over time due to forest fragmentation and loss of food species due to tree felling (ibid).

Overall, the loss of canopy cover at Panadura, where most home gardens were small to medium in 1987, was much higher than anticipated through the questionnaire survey in 1987. Although $>70 \%$ of respondents at the Piliyandala site had anticipated some form of habitat change, the loss of canopy cover was much greater than expected as all home gardens had undergone 
considerable tree felling and habitat change by 2006 . The main underlying factors that influenced home garden fragmentation at Panadura and Piliyandala were greatly elevated land values and an increasing scarcity of land for housing and development activities. This had led to sale of land or dividing home garden among the offspring of the original owners (J.D.S.Dela, unpublished data). The main reasons for tree felling at both sites were the high price of timber for housing and the need to clear land for housing construction. Similar habitat change can be expected in other human-modified areas within the range of $S$. vetulus nestor, as the human population density in this region has risen from 956/ sq $\mathrm{km}$ in 1981 to $1259 / \mathrm{sq}$ $\mathrm{km}$ in 2001 (Department of Census and Statistics, 2001). The 2008-2010 range survey of S. vetulus nestor also indicates strongly that the area it occupies will decrease further due to continual decreasing of canopy cover and food trees, in human modified environments (J.D.S.Dela, unpublished data). Therefore, a considerable population reduction of $S$. vetulus nestor can be expected over time.

Despite a high tolerance of langurs in 1987, most people at both study sites considered monkeys as pests, mainly because of crop raiding and damage to tiled roofs. Crop raiding by langurs is a problem in many parts of Asia (Bernstein, 1968; Oppenheimer, 1977; Eudey, 1987; Mittermeier et al., 2005) where local people use a variety of deterrents to prevent crop raiding and damage to habitations, including destroying monkeys by poisoning and shooting (Bernstein, 1968; Hrdy, 1977; Oppenheimer, 1977). Likewise, during this study, most monkey-human conflicts were due to crop raiding, and a large number of crop protection measures were observed, including shooting. Notably, the number of monkey-human conflicts due to crop raiding was less at the agricultural Piliyandala site than at the Panadura site, although most householders identified the loss of agricultural crops as the prime problem due to monkeys at the Piliyandala site. This was probably because of the low density of houses at this site and the availability of large areas with high and continuous tree cover during the study, which resulted in much of the crop raiding being undetected.

During the systematic study, the damage to roofs caused more monkey-human conflicts at Panadura than at Piliyandala, where most houses were small and had thatched roofs. Hence, larger and permanent housing with high roofs, tree felling and the disruption of important arboreal pathways for monkeys, could be expected to increase monkey - human conflicts, as seen in 2006 and the 2008-2010 survey. Large gaps in canopy trees also force langurs to use inhospitable areas (such as the riverine scrub areas at Piliyandala) and low level arboreal pathways, engage more frequently in ground travel to cross roads, or use power lines to cross gaps in the canopy. These changes make langurs more vulnerable to low food availability, predation by dogs, human harassment and hunting, and injury or death due to electrocution. Consequently, home garden fragmentation, tree felling and urbanization could be expected to increase: (a) monkey-human food conflicts in areas where groups are pocketed, (b) mortality in langur groups, and (c) a population reduction or total extirpation, in human modified areas severely affected by habitat change.

Many primate species are subject to heavy hunting pressure (Eudey, 1987; Mittermeier et al., 2005). Colobines are particularly susceptible as they are easy to detect because of a fairly large body size and the loud calls of adult males (Oates \& Davies, 1994). Few people at both study sites wanted to destroy monkeys, and fewer were directly engaged in hunting to consume flesh or to protect crops. Hunting was however, the main cause of langur mortality, despite: (a) a high tolerance of monkeys in 1987, (b) eschewing of hunting by most householders, and (c) reduced hunting pressure due to interventions by the researcher. This study shows, however, that hunting pressure on $S$. vetulus nestor varied within its range. Other studies support this, and show that in some areas of Sri Lanka, where subsistence or commercial scale agriculture is the main source of livelihood for local people, langurs, including $S$. vetulus are hunted for meat or as agricultural pests (IUCN, 1995). S. vetulus is also hunted for its skin to make traditional drums in some parts of the island (personal communication, Senevi Epitawatte), and langur skins from Dunkanda in the Kurunegala District are reputed to provide the best skins for drums (J.D.S.Dela, unpublished data). Such use was, however, not recorded from any of the seven sites surveyed during this study. The 2008-2011 survey also suggests that hunting was localized; hunting pressure has also dropped in many areas of the $S$. vetulus nestor range where it was considerable about 10-20 years ago, due to the death of the old hunters (J.D.S.Dela, unpublished data). However, S. vetulus nestor populations in such areas are now perceptibly low. It has also been shown that while hunting and trapping may contribute to the decline of primate populations (Mittermeier \& Chenly, 1987; Oates \& Davies, 1994; Mittermeier et al., 2005), the combined effects of both logging and hunting can bring about a more definite population decline, and even local extinction (Oates \& Davies, 1994). Therefore, even low hunting pressure on $S$. vetulus nestor could be a significant threat to populations that are subject to severe habitat degradation. 
Another negative impact of hunting is that hunters generally target the largest and most visible animals (Oates \& Davies, 1994), which for S. vetulus nestor is the adult male. The social organization of $S$. vetulus nestor results in an adult male living in a reproductive group being evicted (or killed) during Adult Male Replacement (AMR) by a more dominant adult male from outside the group (Dela, 1998). Recurrent removal of adult males from reproductive groups due to hunting, can therefore, cause the most dominant males in possession of reproductive groups in a population-and probably those with the best genetic potential-to be replaced by more subordinate males over time. Accelerated AMR due to hunting could also increase the frequency of infanticide in $S$. vetulus nestor (Dela, 1998). Previous studies on $S$. vetulus philbricki at Polonnarurwa, provides evidence that frequent AMR and associated infanticide leads to population decline (Rudran, 1970, 1973). While forest populations may recover from such a decline with time (Rudran, 1970), this may not be possible in S. vetulus nestor populations subject to persistent habitat loss and hunting.

Live capture was not a factor for population decline among $S$. vetulus nestor at any of the surveyed sites during this study, or during the 2008-2010 survey (J.D.S.Dela, unpublished data). Captive animals are generally inhumanly tethered and reared under very poor conditions, and were unfit for reintroduction as free ranging individuals. Although live capture and rearing of this species in captivity is prohibited by law since 1994, institutional facilities are seriously lacking to deal effectively with confiscated captives or injured free ranging animals that are sent to the National Zoological Gardens. Setting up a separate facility for poorly maintained captives, and injured $S$. vetulus nestor that range in home gardens is a vital requirement, but this needs long-term planning and staff training. Until such time when an efficient rehabilitation facility is set-up, a scheme for licensed and supervised captive care of langurs by responsible volunteer members of the public should be seriously considered, according to stipulated guidelines and in collaboration with the National Zoological Gardens and the Department of Wildlife Conservation. Setting up a rehabilitation cum research centre by the National Zoological Gardens should, however, be a priority for this globally threatened langur.

At both sites, and particularly at the more rural Piliyandala site, religious beliefs were important in generating tolerance towards monkeys. Religious and cultural values can, however, erode with time. For example, in India where the grey langur is considered sacred, escalation of secularism and damage caused by monkeys sometimes undermined traditional beliefs, causing large numbers of monkeys to be killed, harassed and even translocated in a haphazard manner. (Southwick et al., 1965; Hrdy, 1977; Oppenheimer, 1977). Similarly, human tolerance towards $S$. vetulus populations could lessen when conflicts between humans and monkeys escalate due to habitat change. The considerable increase in human population pressure and secularism within Sri Lanka during the last three decades, and the ensuing rapid socio-economic development and increased human needs, has increased the demand for land within the range of $S$. vetulus nestor. Continuing changes in land use patterns and pocketing of langurs in limited areas that have adequate canopy cover is already undermining the co-occurrence of humans and langurs that existed for centuries. Better educational levels and educating people about the importance of langurs do not help conservation of this monkey, as it does not halt habitat change due to home garden fragmentation and loss of canopy in human modified areas. For example, habitat change by 2006 at the Panadura site, where the environmental value of monkeys was well understood in 1987, had greatly exceeded envisioned habitat change in 1987; it was also more than the changes seen at the Piliyandala site where the environmental value of the langur was less important in 1987. Clearly, incentives to maintain canopy cover and effective land use planning are necessary to combat severe home garden fragmentation and rapid loss of canopy cover in the western wet lowlands of Sri Lanka.

Overall, the prognosis for the future survival of $S$. vetulus nestor is bleak, due to the paucity of contiguous and large natural forests and protected areas within its geographic range. This study shows that although $S$. vetulus nestor had adapted to, and thrived in human modified habitats in the past, its future survival is precarious due to the vulnerability of such habitats for rapid change. Rapid loss of suitable habitat and increased monkey-human conflicts can be expected with the spread of urbanization and development into rural areas within this region. Smaller home gardens with low canopy cover will result in fewer food sources, arboreal pathways, and sleeping trees for $S$. vetulus nestor, and will increase monkey-human conflicts. Langur populations living in areas that are subject to persistent habitat degradation and hunting may also have low juvenile recruitment. As free ranging langurs may live for 20 years (personal observations, J.D.S.Dela), a precipitous population decline in populations can occur once the existing adults die out. The pocketing of langurs in small habitat patches with canopy cover may also cause isolation of groups and increase the potential for inbreeding and genetic erosion. Further degradation and isolation of the existing 
forest fragments in the $S$. vetulus nestor range will also compound threats to this langur.

In conclusion, the findings of this study underscore the urgent need for institutional action by the Forest Department which manages almost all forest patches within the $S$. vetulus nestor range, supported by action oriented research and conservation projects that will target its survival in the forest fragments and maintaining canopy cover in important village habitats. As there are no single forests that can sustain large population of this langur within their boundaries, action being taken to identify (a) important forest refuges for this langur that could be enriched and linked via non-forest habitat matrices with good canopy cover and (b) non-forested habitats with substantial langur populations should be supported and followed up. It is also critically important that long-term studies are initiated on this Critically Endangered langur to better understand and address the impact of habitat change on its diet, behaviour and genetic composition in both forests and modified areas. The future survival of this taxon will depend very much on how soon and effectively these conservation requirements are addressed.

\section{Acknowledgement}

Financial support provided by the Natural Resources Energy and Science Authority of Sri Lanka (Grant $\mathrm{MAB} / 85 / 1$ ) is acknowledged. I specially thank my chief Ph. D. supervisor Dr W.P.J. Dittus for advice. I also thank Mr. Lyn de Alwis, Prof. S.W. Kotagama, the late Prof. W.R Breckenridge and Dr R. P. Jayawardena for support, and the Aerial Photo Interpretation Division of the Survey Department of Sri Lanka for help with site mapping. I thank the Public Trustee and staff of the Regidale Estate, Piliyandala and home garden owners at all study areas for permission to work at these sites. I am grateful to M. L. Soma Perera, Jane, Aslin and Badra for field assistance, Ms. Neela De Zoysa-Simon for plant species identification and Ms. Gayathree Jayasinghe for statistical advice. I acknowledge useful comments by the external examiner of my Ph. D. thesis Dr Elizabeth Bennett.

\section{REFERENCES}

1. Bernstein I. S. (1968). The Lutong of Kuala Selangor. Behaviour 32: 1-16.

2. Brandon-Jones D., Eudey A. A., Geissmann T., Groves C. P., Melnick D. J., Morales J. C., Shekelle M. \& Stewart C.-B. (2004). Asian primate Classification. International Journal of Primatology 25(1): 97-162.

3. Davies A G. (1994). Colobine populations. Colobine
Monkeys: Their Ecology, Behaviour and Evolution (eds. A.G. Davies and J.F. Oates), pp. 285-310. Cambridge University Press, Cambridge, UK.

4. Dela J. D. S. (1998). The ecology and social biology of a selected population of the western purple-faced leaf monkey (Trachypithecus vetulus nestor = Presbytis senex nestor). Ph.D. thesis, University of Peradeniya, Peradeniya.

5. Dela J. D. S. (2004). To conserve the endemic purplefaced langur. Loris. 23(5 \& 6):14-22.

6. Dela J. D. S. (2007). Seasonal food use strategies of Semnopithecus vetulus nestor, at Panadura and Piliyandala, Sri Lanka. International Journal of Primatology 28(3): 607-626.

7. Dela J. D. S. (in press). Western purple-faced langurs (Semnopithecus vetulus nestor) feed on ripe and ripening fruit in human-modified environments in Sri Lanka. International Journal of Primatology.

8. Department of Census and Statistics (2001). Census of Population and Housing 2001: (population by sex, age, religion, ethnicity according to district and D.S. division) Department of Census and Statistics, P O Box 563, Colombo.

9. Dittus W. P. J. (1977). The sociological basis for the conservation of the Toque Monkey (Macaca sinica) of Sri Lanka (Ceylon). Primate Conservation (eds. H. S. H. Prince Ranier III \& G. H. Bourne), pp. 237-165. Academic Press, New York, USA.

10. Eudey A. A. (1987). IUCN/SSC Primate Specialist Group Action Plan for Asian Primate Conservation: 1987-91. IUCN/SSC Primate Specialist Group, Virginia, USA.

11. Groves C. (2001). Primate Taxonomy. Smithsonian series in comparative evolutionary biology. Smithsonian Institution Press, Washington DC, USA.

12. Gunatilleke C. V. S. \& Gunatilleke I. A. U. N (1985). Phytosociology at Sinharaja - a contribution to rainforest conservation in Sri Lanka. Biological Conservation $31: 21-40$.

13. Hill W. C. O. (1934). A monograph on the purple-faced leaf monkeys (Pithecus vetulus). Ceylon Journal of Science (B) 19(1): 23-88.

14. Hrdy S. B. (1977). The Langurs of Abu: Female and Male Strategies of Reproduction. Harvard University Press, Cambridge, USA.

15. IUCN (1995). Traditional Uses of Natural Forests in Sri Lanka - A National Survey. Vol II. Forest Department of Sri Lanka, Battaramulla.

16. IUCN (2011). 2011 IUCN Red List of Threatened Specie. Version 2011.1. Available at www.iucnredlist.org, Accessed 12 August 2010.

17. Mittermeier R. A. \& Cheney D. L. (1987). Conservation of primates and their habitats. Primate Societies (eds. B. B. Smuts, D. L. Cheney, R. M. Seyfarth, R. W. Wrangham \& T. T. Struhsaker), pp. 477-490. University of Chicago Press, Chicago, USA.

18. Mittermeier R. A., Valladares-Pádua C., Rylands A. B., Eudey A. A., Butynski T. M., Ganzhorn J. U., Kormos R., Aguiar J. M. \& Walker S. (2005). Primates in peril: 
The World's 25 Most Endangered Primates 2004-2006. Conservation International, Washington DC, USA.

19. Ministry of Forestry and Environment (MOFE) (1999). Biodiversity Conservation in Sri Lanka: A Framework for Action. Ministry of Forestry and Environment, Battaramulla.

20. NARESA (1991). Natural Resources of Sri Lanka: Conditions and Trends (ed. M.F. Baldwin). Keels Business Systems, Colombo.

21. Oates J.F. \& Davies A.G (1994). Conclusions: the past, present and future of the colobines. Colobine Monkeys: Colobine Monkeys: Their Ecology, Behaviour and Evolution (eds. A.G. Davies and J.F. Oates), pp. 347-358. Cambridge University Press, Cambridge, UK.

22. Oppenheimer J. R. (1977). Presbytis entellus, the Hanuman langur. Primate Conservation (eds. H. S. H. Prince Rainier \& G. H. Bourne), pp. 469-512. Academic Press, New York, USA.

23. Phillips W. W. A. (1981). Mannual of the Mammals of Sri Lanka, 2nd revised edition. Wildlife and Nature Protection
Society of Sri Lanka, Colombo.

24. Rudran R. (1970). Aspects of ecology of two sub-species of purple-faced langurs (Presbytis senex). M. Sc. thesis, University of Ceylon, Colombo.

25. Rudran R. (1973). Adult male replacement in one-male troops of purple-faced lan-gurs (Presbytis senex senex) and its effect on population structure. Folia Prima-tologia 19:166 -192.

26. Singh S. D. (1969). Urban monkeys. Scientific American 221(1): $108-115$

27. Southwick C. H., Beg M. A. \& Siddiqi M. R. (1965). Rhesus monkeys in North India. Primate Behavior (ed. I. De Vore), pp. 111-159. Holt, Rinehart and Winston, New York, USA.

28. Struhsaker T. T. \& Leland L. (1987). Colobines: infanticide by adult males. Primate Societies (eds. B. B. Smuts, D. L. Cheney, R. M. Seyfarth, R. W. Wrangham \& T. T. Struhsaker), pp.83-97. University of Chicago Press, Chicago, USA. 